\title{
TEORIA DO KARMA, SISTEMA DAS CASTAS E CONCEITO DA REENCARNAÇÃO E SEU IMPACTO NA SOCIEDADE INDIANA: UMA LEITURA ANTROPO-FILOSÓFICA
}

\author{
Theory of Karma, Caste System and Concept of Reincarnation and their Impact on \\ Indian Society: An Anthropo-Philosophical Reading
}

Joachim Andrade ${ }^{1}$

\begin{abstract}
RESUMO: Este artigo pretende realizar uma aproximação à sociedade indiana a partir de três conceitos distintos da tradição hinduísta: a teoria do Karma, a reencarnação e o sistema das castas. Esses três pilares sustentam todo o universo familiar, social e religioso, parecendo, por vezes, que o indivíduo está eternamente preso sem encontrar uma saída. O artigo apresenta os mecanismos envolvidos na construção desses três pilares, e, também, mostra os caminhos adequados para saída elaborados pelo hinduísmo. No primeiro momento, faz-se o mapeamento da tradição hinduísta onde se contempla a construção da divindade, conhecida como tríade hindu, e, em seguida, desenvolvem-se os três pilares em forma sequencial, finalizando com a abordagem dos princípios éticos de vida que são os aspectos que mantém o hinduísmo vivo ainda hoje.
\end{abstract}

PALAVRAS-CHAVE: Hinduísmo; Karma; Reencarnação; Castas; Salvação.

ABSTRACT: This article intends to make an approximation to Indian society from three distinct concepts of Hindu tradition: Karma theory, reincarnation and caste system. These three pillars sustain the entire social system which includes family, society and religion, such a way that sometimes it seems that the individual is perpetually imprisoned in it without finding a way out. The article presents the mechanisms involved in the construction of these three pillars and also shows the appropriate paths elaborated by Hinduism. At the first moment we intend to map the Hindu tradition, which contemplates the construction of the Hindu Trinity and then presents the three pillars in a sequential way and finally winds up with the treatment of Hindu ethical principles of life that keep Hinduism alive even today.

KEYWORDS: Hinduism; Karma; Reincarnation; Caste; Salvation.

\footnotetext{
${ }^{1}$ Doutor em ciências da religião pela Pontifícia Universidade Católica de São Paulo (PUC-SP), professor de teologia na Pontifícia Universidade Católica do Paraná (PUCPR) e no Claretiano - Centro Universitário. E-mail: joachimandrade@terra.com.br
} 
Os três assuntos, a teoria do Karma ${ }^{2}$, o sistema das castas e a reencarnação, sempre suscitaram a curiosidade nos estudiosos de Ciências da Religião do Ocidente. O conceito do Karma possui a abrangência universal. A reencarnação é o aspecto central de algumas tradições indígenas e africanas, enquanto o sistema das castas, todavia permanece como patrimônio da sociedade indiana.

$\mathrm{Na}$ sociedade indiana estes conceitos, além de terem raízes profundas, estendem-se, também, à ramificação de todas as camadas da vida familiar, social e espiritual. $\mathrm{O}$ indivíduo atribui qualquer infortúnio experimentado ao Karma: - "Meu karma, fiz algo errado na vida passada e agora estou pagando por isso". A sociedade ocidental, que foi predominante cristã, parece ter um entendimento sobre a teoria kármica. Diz-se: o que é semeado irá se colher. O que mais intriga é que na sociedade indiana esse discurso é estendido às outras esferas, como a vida anterior e a posterior, consequentemente se vinculando e se amarrando os três conceitos em um único conjunto. A tradição hindu sempre se apresenta numa forma sincrética $^{3}$. Karma, reencarnação e sistema das castas, portanto, devem ser abordados juntos, como também uma meticulosa consulta aos princípios éticos da tradição hinduísta.

A teoria do Karma, vinculada à reencarnação, não é um patrimônio fechado do hinduísmo da Índia. A crença da reencarnação existe em muitas religiões indígenas ou africanas com algumas divergências distintas de uma para a outra. Serve de exemplo o espiritismo brasileiro, no qual existe este conceito com uma abordagem diferente, existindo um processo evolutivo da alma. Acredita-se que esta se encontre sempre em estado de evolução, rumo à perfeição, estado este no qual não existe a possibilidade de regredir. Na compreensão hinduísta existe o caminho de evolução, de involução, além de outros rumos horizontais com os seres animados e inanimados. Essa complexidade levou inúmeros estudiosos como Louis Dumont, Mircea Eliade, Joseph Campbell, Octavio Paz e outros a analisarem esse conceito em perspectivas diferentes. Todos reconheceram a dificuldade de apresentar uma compreensão nítida desta sociedade dada a sua própria natureza.

Neste artigo não se pretende, portanto, fornecer uma visão conjunta dos três conceitos, tentando fazer uma aproximação aos brasileiros para compreenderem melhor a sociedade

\footnotetext{
${ }^{2}$ Em língua portuguesa, a palavra Karma também é escrita como Carma. Neste artigo se mantém a sua forma original.

${ }^{3}$ Existem duas formas de construir uma sociedade: diacrônica e sincrônica. O Ocidente sempre teve a visão diacrônica, onde a análise é feita a partir das partes para ter uma visão do todo. Enquanto, a sociedade indiana teve o caminho sincrônico - o todo desdobrando em partes para ter uma visão do conjunto.
} 
indiana nos tempos atuais. Para este procedimento se fará uma apresentação geral sobre a tradição hinduísta na qual esses conceitos receberam sua origem e identidade. Numa segunda instância serão analisados os três conceitos separadamente, com as perspectivas diferentes. Pretende-se, igualmente, abordar os aspectos relativos a esses conceitos, os princípios éticos hinduístas que os sustentam.

\section{Visão geral do hinduísmo}

O nome tradicional do hinduísmo é Sanatana Dharma, cujo significado é Religião Eterna. $\mathrm{O}$ vocábulo hinduísmo foi inventado pelos muçulmanos ao invadirem a Índia. Numa tentativa de manter a pureza do islamismo, criou-se o termo para designar a religião do povo que vivia do outro lado do rio Sindhu.

Existe uma teoria evolucionista sobre a origem da civilização indiana. Por volta do ano 2500 a.C. um grupo de nômades chamado árias, do norte do Irã, deixou sua realidade do deserto e emigrou em seis direções.

Os grupos que se dirigiram ao Ocidente espalharam-se por toda a Europa, tornando-se os ancestrais dos povos gregos, romanos, celtas, germânicos e eslavos, já os que tomaram a direção do Oriente, dos indianos. ${ }^{4}$

Ao invadirem a Índia, os árias encontraram nativos chamados drávidas, conhecido como o povo da agricultura. Os nômades, com sua índole guerreira, estabeleceram a supremacia sobre os nativos, inculturaram-se. Do encontro dessas duas culturas originouse uma complexa religião ritualística conhecida como védica. Posteriormente, assume diversos nomes como brahmanismo, sanatana dharma e, finalmente, o hinduísmo.

Pode-se afirmar, assim, que o hinduísmo é a religião dos nômades que perderam suas raízes e assumiram as características de um povo cujo pensamento se encontra enraizado na cultura agrícola, como resume Radhakrishnan: "a facilidade com que o hinduísmo absorveu constantemente os costumes e ideias dos povos com quem entrou em contato é tão grande quanto a dificuldade que sentimos em encontrar uma característica comum que une as suas diferentes formas". 5

\footnotetext{
${ }^{4}$ Existem várias teorias sobre entrada dos povos no subcontinente indiano. Mas a teoria de Max Muller que diz que foram os arianos da Ásia central ainda sustenta os argumentos no campo linguístico e no campo religioso. Cf. CEPEUSP. Estudos sobre o Yoga. v. 1. São Paulo: 2003, p. 24

${ }^{5}$ RADHAKRISHNAN, Sarvapalli. Hindu View of Life. London: Unwin Books, 1927, p. 3.
} 
Nestas assimilações ocorrem as transformações entre as quais se identifica a mudança de uma visão linear para uma cíclica, a passagem do mundo deserto ao agrícola. A partir desse contexto surge o universo religioso carregado de símbolos entre os quais a teoria do Karma veio prevalecer até aos tempos atuais.

A fase inicial do hinduísmo era embasada na preservação da ordem rta, que engloba a dimensão da interconexão e interdependência entre o universo de cima com a realidade de baixo.

A realidade cima era o mundo dos deuses exigindo os sacrifícios centrados ao redor do fogo que os mantinha agradáveis, devido a chama que subia até eles.

O mundo de baixo era o dos seres humanos. Necessitavam eles das chuvas que eram enviadas pelas divindades para a agricultura. Realizavam-se, portanto, sacrifícios para agradá-los. Essa dependência mútua mantinha a ordem do universo. O mundo védico era essencialmente da casta brâmane, pois exercia controle sobre os sacrifícios. "Todo o universo estava centrado ao redor do fogo sacrificial (yajna) e era determinado que dependia do ato ritualístico realizado pelos sacerdotes". 6

Mais tarde, no processo de estratificação da sociedade, surge reação violenta aos rituais e sacrifícios elaborados pelos brâmanes e preocupação pelo antropocentrismo ${ }^{7}$. Nele, o ser humano recebe suma importância e dele se originam duas diferentes concepções do mesmo único Deus Brahman: Nirguna Brahman, o infinito, distante e impessoal, e Sadguna Brahman, o finito, relacional e pessoal. Pode-se dizer que as duas naturezas se encontram no mesmo Brahman e, por vezes, apresentam-se como transcendentes: Nirguna, e, em outras circunstâncias com qualidades relacionais, Sadguna. É relevante notar que a passagem do Nirguna para Sadguna Brahman foi um passo muito importante, quando a classe sacerdotal começa a perder seu espaço religioso até então manipulado por ela.

\footnotetext{
${ }^{6}$ NEUNER, J. Bhagavad Gita. In: DE SMET, R.; NEUNER, J. (ed). Religious Hinduism. Mumbai: St. Pauls, 1997, p. 281.

${ }^{7}$ Entre os protestos contra rituais é prudente mencionar a origem do budismo e jainismo, duas tradições dissidentes do próprio hinduísmo que levaram fiéis a abandonarem a tradição védica ritualística. $\mathrm{O}$ budismo dá ênfase para a busca racional a partir da compreensão da condição humana, enquanto o jainismo elaborou o caminho a partir da não violência. As duas tradições nasceram no século $\mathrm{V}$ antes de Cristo na bacia do rio Ganges.
} 


\subsection{Processo de construção da tríade hindu}

Por volta do século $\mathrm{V}$ antes de Cristo o antropocentrismo se tornou central no pensamento indiano. O Sadguna Brahman era considerado "visível não só no templo e santuário, mas também em todo o fluxo de vida - na natureza, nas pessoas, no nascimento, crescimento e morte". ${ }^{8}$ O divino se encontra numa forma oculta no ser humano presente, mas continua sendo transcendente. O termo Nirguna Brahman era utilizado para preservar a transcendência, enquanto Sadguna Brahman servia para elaborar sua imanência.

O antropocentrismo se encontra na visão da imanência elaborado pelos Upanishads. Também são as sagradas escrituras posteriores que dão a ênfase mais para a busca divina a partir das práticas meditativas. Ao se tratar o Sadguna Brahman, foi elaborada, igualmente, a imagem da tríade hindu Sadguna Brahman, com qualidades de Brahma, Vishnu e Shiva, respectivamente criação, preservação e transformação. Esses três atributos, outros nomes e formas desse mundo, são as transformações desse mesmo Brahman. Na agricultura, encontra-se o processo cíclico e contínuo da preparação da terra, semeadura, crescimento da planta e a sua colheita e a morte. Esse processo cíclico e contínuo foi aplicado tanto à divindade quanto à vida dos seres humanos.

$\mathrm{O}$ encontro de duas culturas resultou em transformações. $\mathrm{O}$ povo assume a visão cíclica, formula as divindades em um único conjunto, a tríade Brahma, Vishnu e Shiva. Os dois primeiros são supostamente a síntese das divindades trazidas do deserto ao mundo dos nômades, e o último incorporado dos nativos. Uma síntese elaborada na tríade hindu, que contempla a unidade na diversidade dos povos distintos. Além disso, encontra-se uma abordagem antropomórfica dessa tríade hinduísta apresentado numa forma brilhante pelo Radhakrishnan:

Se analisarmos o conceito de personalidade, descobrimos que ele inclui cognição, emoção e vontade, e Deus é visto como o conhecedor supremo, o grande amante, e a vontade perfeita, Brahma, Vishnu, Siva. Estes não são três centros independentes de consciência, como representa a teologia popular, mas três lados de uma personalidade complexa. As diferentes imagens de Deus que prevaleceram no país eram afiliadas a uma ou outra dessa trindade. ${ }^{9}$

No livro de Bhagavad Gita, encontra-se o desenvolvimento de uma nova ordem sociológica, onde o discurso não é mais o sacrifício, mas o dharma (lei e ordem). A perspectiva de Bhagavad Gita afirma que as crenças que ajudam e promovem a vida

\footnotetext{
${ }^{8}$ ECK, Diana. Darsan: Seeing the Divine Image in India. New York: Columbia University Press, 1985, p. 10.

${ }^{9}$ RADHAKRISHNAN, Sarvapalli. Hindu View of Life. London: Unwin Books, 1927, p. 21.
} 
espiritual devem estar em consonância com a natureza e as leis que regem o mundo. Um dos objetivos das crenças é alcançar e propor ao homem caminhos para atingir a harmonia com o restante do cosmos. A partir dessa visão e experiência, a fé hindu é construída, afirmando que "a fé é a visão da alma, aquele poder pelo qual as coisas espirituais são aprendidas, assim como as coisas materiais são aprendidas pelos sentidos físicos". ${ }^{10}$

Quando se considera a fé nessa forma, a religião poderia ser vista como fé ou intuição. A fim de se poder traduzir certeza religiosa em certeza lógica, é necessário utilizar uma linguagem intelectual para a experiência da Divindade. Essa compreensão ainda prevalece hoje embora existam novas roupagens elaboradas conforme novos contextos.

O que se bloqueia para realizar a experiência da divindade é a ignorância. Os indianos utilizam o termo Maya, por vezes também traduzido como ilusão. Esta é adquirida quando os sentidos humanos entram em contato com o mundo fenomênico eliminando a visão do próprio Divino. Para reparar e justificar esse problema, o hinduísmo desenvolveu, posteriormente, outros temas como reencarnação, o complexo sistema das castas, além de apresentar os princípios éticos de vida, todos intimamente vinculados à teoria do Karma que se tratará a seguir.

\section{Teoria do Karma}

O termo Karma provém de "kri", do sânscrito, que significa "para fazer" ou "agir e reagir". Pode-se entender esse conceito com o princípio universal da causa e efeito, ação e reação, que os hindus acreditam que governa a consciência humana. O karma se refere à totalidade das ações humanas e às reações produto dessas ações, seja nesta vida ou na vida anterior que determina o futuro do ser humano. O hinduísmo afirma que "o carma é produzido em quatro formas: com pensamentos, palavras, as nossas ações e as ações dos outros, guiadas por nossas instruções". ${ }^{11}$

Toda a crença religiosa hinduísta, ou a teodiceia hindu, está intimamente vinculada à teoria do Karma que, às vezes, é interpretada como a negação da liberdade humana, geralmente considerada como base para todos os valores éticos. A compreensão do Karma, muitas vezes chamado de "lei do Karma", é uma espécie de mecanismo cósmico de equilíbrio do qual ninguém pode escapar.

\footnotetext{
${ }^{10}$ RADHAKRISHNAN, Sarvapalli. Hindu View of Life. London: Unwin Books, 1927, p. 14.

11 ANDRADE, J. Índia, lar dos deuses e terra das multidões: uma aproximação às religiões indianas. Curitiba: Intersaberes, 2019, p. 39.
} 
A presente existência é configurada e determinada pelas ações [karma] de uma existência prévia, que por si só foi o resultado das ações de uma existência anterior, e assim sucessivamente numa série de vidas sem início definido, submetidas a um determinismo cego de rígida retribuição. ${ }^{12}$

Existem, também, outros entendimentos, pois o karma é interpretado como o que está ligado ao mundo material ou ao contexto em que um indivíduo se desenvolve. À medida que esse princípio considera o passado como fator determinante, afirma que o futuro também é condicionado. Como um provérbio hindu, "o bem que fizemos na véspera é o que nos traz a felicidade pela manhã". Segundo essa perspectiva, tudo é resultado de uma ação anterior.

A teoria do Karma também é, muitas vezes, confundida com predeterminação, quando se percebe a queda em desgraça de alguém que se encontrava bem anteriormente. Para essa pessoa é dito: "não é que você é um ser amaldiçoado, mas isso é tudo que você poderia ter sido. Isso era pré-ordenado a você, desde o início dos tempos". ${ }^{13}$

Um dos monges e também pensador da tradição hinduísta da corrente do Movimento Hare Krishna, Swami Vivekananda, faz uma abordagem diferente. Afirma ele: "karma é a eterna afirmação da liberdade humana... nossos pensamentos, nossas palavras, nossos atos, são fios de uma rede que tecemos ao redor de nós mesmos". ${ }^{14}$

Esta afirmação é enfatizada e complementada por Deepak Chopra, o aclamado médico contemporâneo: "Toda ação gera uma força energética que retorna a nós da mesma forma. O que semeamos é o que colhemos". ${ }^{15}$ Segundo esta abordagem, as escolhas determinam suas próprias consequências, e, portanto, deve-se estar "conscientemente alerta para as escolhas que fazemos a todo o momento". ${ }^{16}$

Existem outras interpretações mais moderadas e esperançosas, pois quando esse princípio é visto na forma correta, a lei do Karma não entra em conflito com a afirmação da liberdade. O Karma pode ser visto como o princípio da ciência que desloca a crença na magia, segundo a qual os seres humanos são capazes de dominar a natureza segundo seus prazeres. O curso da natureza está determinado não pelas paixões dos espíritos particulares, mas pela operação das leis imutáveis. Ainda outros pensam que Karma não

\footnotetext{
${ }^{12}$ ANTOINE, R. Hindu Ethics: General Ethics. In: DE SMET, R.; NEUNER, J. (ed). Religious Hinduism. Mumbai: St. Pauls, 1997, p. 153.

${ }^{13}$ RADHAKRISHNAN, Sarvapalli. Hindu View of Life. London: Unwin Books, 1927, p. 55.

${ }^{14}$ VIVEKANANDA, Swami. O que é religião. Rio de Janeiro: Lótus do Saber, 2004, p. 87.

${ }^{15}$ CHOPRA, Deepak. As sete leis espirituais do sucesso: um guia prático para a realização de seus sonhos. São Paulo: Editora Best Seller, 1994, p. 37.

${ }^{16}$ Ibid., p. 39.
} 
é um princípio mecânico, mas uma necessidade espiritual, uma incorporação da mente e desejo de Deus.

A justiça é um atributo de Deus [...]. O Dia do Julgamento não está em um futuro mais remoto, mas aqui e agora, e ninguém pode escapar dele. As leis divinas não podem ser evitadas. Elas não são tanto um desafio de Deus como uma negação de alma, não tanto uma violação da lei como uma traição de si mesmo. Carregamos conosco todo o nosso passado. É um registro imutável que o tempo não pode borrar nem apagar a morte. ${ }^{17}$

Uma outra interpretação, tida por moderna, afirma que a teoria do Karma considera os seres humanos espirituais. O elemento espiritual permite ao ser humano ter a liberdade nos limites de sua natureza humana. O espírito interno pode triunfar sobre os mecanismos automáticos que mantêm os seres humanos presos aos instintos repetitivos. Para compreender a dinâmica desse processo, o hinduísmo introduz outro conceito chamado de samsara. É compreendido como estar preso sempre à roda da vida ou a um ciclo de causas e efeitos e aos de reencarnações. Somente a natureza espiritual, adquirida com a prática de princípios éticos, poderá sobrepor-se a um quotidiano repetitivo e mecânico. Os caminhos apresentados ao desenvolvimento da natureza espiritual são três: do conhecimento, do serviço e da devoção.

\section{Compreensão da reencarnação}

A crença da reencarnação existe em muitas religiões e seus conceitos divergem de uma para a outra. No espiritismo brasileiro, por exemplo, este conceito recebe uma abordagem diferente. Acredita-se que a alma se encontra sempre em estado de evolução, rumo à perfeição, não existindo a possibilidade de regredir.

A tradição hinduísta possui outra abordagem, propondo uma síntese na qual a criação acontece a partir da desintegração do corpo de Deus. A salvação é o retorno a esse corpo Divino. O Uno se desdobra na multiplicidade e esta deseja retornar ao Uno. É importante se observar que na sociedade hindu as pessoas procuram viver esse retorno a partir dos princípios éticos. Alguns conseguem atingir em uma única existência. Outros precisam passar por várias, de um estágio para outro, experimentando infinitos nascimentos e renascimentos em formas de semideuses, humanos, animais, vegetais e inanimados.

A série de sucessivos nascimentos conhecida como samsara, como se apontou acima, é comparada com o oceano, que passa por constantes experiências de turbulência. Nesse

\footnotetext{
${ }^{17}$ RADHAKRISHNAN, Sarvapalli. Hindu View of Life. London: Unwin Books, 1927, p. 53.
} 
conceito de samsara, a possibilidade da libertação do indivíduo está na moralidade de uma existência correta segundo o dharma, princípios estabelecidos pela tradição. Há duas abordagens distintas, complementares, que podem esclarecer o conceito de samsara. Ambas são de Katha-Upanishad. A primeira afirma que "o Homem se encontra na escravidão de samsara: como o milho, é colhido quando maduro, como o milho, torna a brotar" (I,1,6). A segunda aponta:

O homem sábio discerne valores espirituais: escolhe o bem ao invés do mal. Aqueles que não são sábios, escolhem o que lhes dá prazer, e aqueles que acreditam que este mundo existe e outro não, caem repetidamente no domínio da morte. ${ }^{18}$

No delineamento de sua conduta moral, o hinduísmo oferece a possibilidade da moksha, ou libertação de samsara. Uma vez que toda a criação é concebida como extensão de Deus e com retorno inevitável, não importa nascer como flor, formiga ou ser humano. Cada elemento é uma extensão da divindade, capaz, portanto, de retornar. À luz deste entendimento, os hindus consideram que todo o universo é a vibração constante da presença de Deus.

Assim, nada do que o indivíduo recebe é por acaso. O que prende o ser humano à samsara é a ignorância causada pelo desejo e pelo prazer. Para se libertar destas duas amarras, há de compreender, por si só, sua condição e procurar libertar-se. O cristianismo tem outro modo de trabalhar, sustentando que outro ser, o Emanuel, pode alcançar a redenção. Como afirma Octavio Paz, "no asceticismo cristão, o conceito central é a redenção, e no da Índia, libertação". ${ }^{19}$ No hinduísmo, cada indivíduo é arquiteto de sua própria vida. Para realizar tal obra, recebe princípios para orientar-se em sua conduta e, por fim, libertar-se.

\section{Sistema das castas}

A extensão do tema da reencarnação leva a tratar o complexo sistema das castas que também remete suas raízes à samsara, o que determina um indivíduo a nascer numa determinada casta.

O sistema das castas se tornou uma característica da vida social e religiosa na Índia, desde 800 a.C. ainda que as raízes de sua existência remetam aos tempos remotos. O

${ }^{18}$ I,2,1-6, apud ANTOINE, R. Hindu Ethics: General Ethics. In: DE SMET, R.; NEUNER, J. (ed). Religious Hinduism. Mumbai: St. Pauls, 1997, p. 156.

${ }^{19}$ PAZ, Octavio. Vislumbres da Índia: um diálogo com a condição humana. São Paulo: Mandarim, 1995, p. 144 . 
nome hindu para a casta é "jati". Significa espécie, tipo que pertence a um grupo fechado. O maior pesquisador sobre o sistema das castas, Louis Dumont, antropólogo francês, afirma:

As castas são, antes de tudo, realidades sociais: família, língua, ofício, profissão, território. São uma ideologia: uma religião, uma mitologia, uma ética, um sistema de parentesco e uma dietética. São um fenômeno: não é explicável a não ser dentro e a partir da visão hindu do mundo e dos homens. ${ }^{20}$

O sistema das castas é uma hierarquia social e religiosa que determina casamentos e funções sociais.

As principais castas são determinadas pelas sagradas escrituras, no hino X, versículo 90. São quatro, apresentadas da seguinte forma:

a) Brâmane: possui como origem a emanação a partir da cabeça de Brahma; sua função social é sacerdotal. b) Ksatriya: possui como origem a emanação a partir dos braços de Brahma; sua função social é nobreza e guerra. c) Vaiysia: sua emanação decorre das pernas de Brahma e, por isso, sua função diante da sociedade é o trabalho liberal. d) Sudra: possui como origem a emanação a partir dos pés de Brahma; sua função social é a execução do trabalho manual. ${ }^{21}$

Ao longo dos séculos, o hinduísmo desenvolveu uma estrutura complexa e rígida sobre quatro castas. Como aponta Octavio Paz:

Dentro das três categorias superiores, duas estão compostas por indivíduos duas vezes nascidos e daí sua superioridade: os brâmanes e os ksatriyas. A divisão, segundo pensa Dumézil, foi tripartida em sua origem e corresponde a três funções tradicionais dos indo-europeus, tal como se vê em sua mitologia: deuses que regem a ordem cósmica, deuses guerreiros e deuses que a conservam ou a mantêm com sua atividade. $^{22}$

Cada casta (explicada teologicamente pelas emanações de Brahma) possui um estatuto próprio. As obrigações vivenciadas em vida possibilitam a reencarnação em uma casta superior, até a purificação total da alma, no seu retorno para Brahma. Essas reencarnações são uma espécie de exigência da justiça. Daí a passividade hindu diante das discriminações das castas. Definem-se desta forma as subdivisões da sociedade: havia a classe nobre, formada por sacerdotes e guerreiros, e as classes baixas, pelo povo em geral. ${ }^{23}$ Posteriormente, o sistema se desenvolveu de tal forma que, na atualidade, existem mais de três mil castas, cada uma com características próprias, rituais, regras de parentesco, tabus sexuais e alimentares. Um dos mistérios que ninguém conseguiu

\footnotetext{
${ }^{20}$ PAZ, Octavio. Vislumbres da Índia: um diálogo com a condição humana. São Paulo: Mandarim, 1995, p. 58.

${ }^{21}$ Existem também outras castas, às vezes chamadas Pária, ou outras vezes Dalit. São os excluídos que se encontram fora do sistema das castas. Por isso, são intocáveis e desprezados.

${ }^{22}$ PAZ, op. cit., 1995, p. 59.

${ }^{23}$ JOHANNS, P. "General historical survey". Part I (B.C. 1200 - A.D. 700). In: DE SMET, R.; NEUNER,

J. (ed). Religious Hinduism. Mumbai: St. Pauls, 1997, p. 31.
} 
explicar é sobre qual a origem das castas e por que elas estão na Índia. Sabe-se, todavia, como elas operam e em que consistem no sistema social indiano.

\section{Princípios éticos de vida}

Os princípios de vida estabelecidos pelo hinduísmo, para viver uma vida eticamente correta, podem ser resumidos em quatro aspectos específicos: artha, kama, dharma e moksha. Como aponta Octávio Paz, estes princípios têm sua própria dinâmica, um sustenta o outro.

O primeiro refere-se à vida prática, ao mundo dos ganhos e das perdas, dos êxitos e fracassos; o segundo, domínio do prazer e da vida sexual, não está regido pelo interesse, mas pelo desejo; o terceiro compreende a vida superior: o dever, a moral e os princípios que norteiam a conduta de cada um diante de sua família, sua casta e a sociedade; o quarto consiste na libertação das cadeias da existência. Todas as quatro finalidades são legítimas. Porém, na escala de valores, o prazer é superior ao trabalho, o dever ao prazer, e a libertação aos outros três. ${ }^{24}$

Esses princípios se encontram atrelados a partir de outro conceito relativamente complexo, mas fundamental, chamado Varnashramadharma. Para que se possa compreender melhor é necessário subdividi-lo em três: varna, ahrama e dharama, cada um com suas explicações próprias.

Varna significa "cor". Os arianos, de pele clara, discriminaram os nativos indianos de pele escura, no início do processo de aculturação. Esta atitude, possivelmente, deu a origem ao sistema das castas.

Ashrama, o segundo aspecto, consiste em quatro fases que cada ser humano deve vivenciar ao longo de sua vida. A primeira fase, brahmacharya, que vai até os 25 anos, é dedicada aos estudos para que se aprendam e se adquiram conhecimentos e sabedoria. A formação impede as expressões emocionais, como o namoro, que prejudica o crescimento intelectual durante a fase que vai até os estudos superiores. A segunda, grahasta, dos 25 aos 50 anos, é uma vida em família. O indivíduo se casa, e, através do trabalho, procura manter sua família e dar formação aos filhos. A terceira, vanaprastha, dos 50 aos 75 anos, é o afastamento para a vida eremítica. Em geral, a pessoa deve se retirar às montanhas para meditar e refletir. A última fase, a sanyasa, dos 75 aos 100 anos, é uma passagem para a vida ascética, significando um desapego completo em relação ao mundo e à família. O ashrama é o sistema que impulsiona o indivíduo a evoluir gradativamente de um estado para outro.

\footnotetext{
${ }^{24}$ PAZ, Octavio. Vislumbres da Índia: um diálogo com a condição humana. São Paulo: Mandarim, 1995,
} p. 151) 
O dharma, apesar de vir a ser interpretado como "religião", nas línguas modernas, tem o significado clássico de retidão, ou boa prática ética, de acordo com os princípios transmitidos de era em era pelos ancestrais virtuosos. Dharma designa a tradicional ordem estabelecida, que inclui todos os deveres, sejam eles individuais, sociais ou religiosos. Na Índia, a maior ênfase está na vivência moral, na qual o hindu é convidado para se prevenir de três inimigos: kama (desejo), lobha (egoísmo) e krodha (raiva), além de cultivar oito virtudes: compaixão por todas as criaturas, paciência, contentamento, puridade, seriedade, pensamento favorável, libertação da avareza e inveja. ${ }^{25}$ Enquanto a lei do karma faz da vida humana um affair puramente individual, o dharma sublinha os deveres sociais de cada hindu.

Cabe trazer à memória o conceito utilizado por Turner ${ }^{26}$ citando Uberoi, o "Varnashramadhrarma," para elaborar o princípio do Karma. O conceito Varnashramadharma subdivide-se em varna, conduz a ideia geral ao sistema das castas. Ashrama, o sistema social e da família tem o intuito de guiar o indivíduo a evoluir gradativamente de um estado para o outro. Dharma é interpretado como religião, Ética, Verdade, estilo de vida e o Dever (ou Lei Universal), procurado por todos. A vivência adequada do dharma liberta o indivíduo do sistema do varna a sair da casta para a nãocasta, no sentido do ashrama, eleva-o da ilusão e ignorância para a perfeição ou iluminação. Nessa forma percebe-se que a finalidade é libertar-se tanto da hierarquia social como da imperfeição individual.

Para que sejam postos em prática tais princípios, o hinduísmo oferece caminhos distintos, diferentes, ao mesmo tempo igualmente valorizados, que podem ser escolhidos por cada hindu e seguidos para o alcance da meta divina da salvação. Como afirma Janssen:

Cada pessoa tem caráter e talentos próprios. Para alguém com tendências filosóficas, o caminho do conhecimento (jnana) é o correto, enquanto para alguém com tendências práticas, é o das ações (karma). A pessoa disciplinada optará pela senda do autocontrole espiritual (yôga) e a devotada, pela da adoração (bhakti). ${ }^{27}$

Assim, entende-se que os princípios éticos sustêm os três pilares (Karma, reencarnação e castas) do hinduísmo e, consequentemente, toda a sociedade indiana, inclusive nos tempos atuais.

\footnotetext{
${ }^{25}$ Cf. ANTOINE, R. Hindu Ethics: General Ethics. In: DE SMET, R.; NEUNER, J. (ed). Religious Hinduism. Mumbai: St. Pauls, 1997.

${ }^{26}$ TURNER, Victor. O Processo Ritual: estrutura e anti-estrutura. Petrópolis: Vozes, 1974.

27 JANSEN, J. (compiladora). O livro das Imagens Hinduístas. São Paulo: Totalidade Editora LTDA, 1995, p. 4.
} 


\section{Conclusão}

A teoria do Karma, o conceito da reencarnação e o sistema das castas, desenvolvidos no subconsciente indiano, encontram-se no sistema religioso hinduísta, um dos mais antigos do mundo.

O hinduísmo inicialmente era conhecido como religião védica, pelos seus complexos ritos. Passou a ser chamado de bramanismo, por motivo da dominação da classe brâmane e, por fim, tem o nome atual, o hinduísmo. É um símbolo de unificação de toda a diversidade indiana. Essa tradição não somente conseguiu desenvolver os três conceitos, como também os preservou até os tempos atuais, com novas roupagens de interpretações. Esses conceitos são bem enraizados desde milênios, tanto no modo de ser, de crer e de relacionar, em todas as camadas da população.

$\mathrm{Na}$ Índia existem as convivências harmônicas entre antiguidade e modernidade e ninguém muda os três pilares, pois são entendidos como way of life ou estilo de vida, inclusive na contemporaneidade.

\section{Referências}

ANDRADE, J. Índia, lar dos deuses e terra das multidões: uma aproximação às religiões indianas. Curitiba: Intersaberes, 2019.

ANTOINE, R. Hindu Ethics: General Ethics. In: DE SMET, R.; NEUNER, J. (ed). Religious Hinduism. Mumbai: St. Pauls, 1997.

CEPEUSP. Estudos sobre o Yoga. v. 1. São Paulo: 2003.

CHOPRA, Deepak. As sete leis espirituais do sucesso: um guia prático para a realização de seus sonhos. São Paulo: Editora Best Seller, 1994.

DE SMET, R; NEUNER, J. Religious Hinduism. Mumbai: St. Pauls, 1997.

DUMONT, Louis. Homo Hierarchicus: The Caste System and Its Implications. Translated by Mark Sainsbury, Louis Dumont, Basia Gulati. Chicago: The University of Chicago Press, 1980.

ECK, Diana. Darsan: seeing the Divine Image in India. New York: Columbia University Press, 1985.

JOHANNS, P. "General historical survey". Part I (B.C. 1200 - A.D. 700) In: Religious Hinduism. DE SMET, R.; NEUNER, J. (ed). Mumbai: St. Pauls, 1997. 
JANSEN, J. (compiladora). O livro das Imagens Hinduístas. São Paulo: Totalidade Editora LTDA, 1995.

NEUNER, J. Bhagavad Gita. In: Religious Hinduism. DE SMET, R.; NEUNER, J. (ed). Mumbai: St. Pauls, 1997.

PARTHASARATHY, A. The Symbolism of Hindu Gods and Rituals. Bombay: Arun Mehata Vakil and Sons LTD, 1985.

PAZ, Octavio. Vislumbres da Índia: um diálogo com a condição humana. São Paulo: Mandarim, 1996.

RADHAKRISHNAN, Sarvapalli. Hindu View of Life. London: Unwin Books, 1927.

TURNER, Victor. O processo ritual: estrutura e anti-estrutura. Petrópolis: Vozes, 1974.

UBEROI, J. Five Symbols of Sikh Identity. In: MADAN, T. (ed). Religion in India. London: Oxford University Press, 1992.

VIVEKANANDA, Swami. O que é religião. Rio de Janeiro: Lótus do Saber, 2004. 